\title{
Mulheres negras, religiosidades e protagonismos no cinema brasileiro
}

Tania Montoro

Ceiça Ferreira

Resumo: Este artigo busca identificar ressonâncias entre o papel central do feminino nas religiões afro-brasileiras e as construções imaginárias sobre "mães de santo" no cinema brasileiro, por meio dos filmes Pureza Proibida (Alfredo Sternheim, 1974) e Besouro (João Daniel Tikhomiroff, 2009). A partir dos estudos culturais, da crítica feminista e da teoria do cinema, propõe-se discutir o cruzamento das identidades de gênero e raça e observar formas de visibilidade e múltiplas configurações do feminino negro nessas narrativas audiovisuais.

Palavras-chave: feminino negro; cinema brasileiro; análise fílmica.

Abstract: Black women, religiosities and protagonism in Brazilian cinema-This study seeks to identify similarities between the central role of the feminine in Afro-Brazilian religions and in the imaginary constructs about "saint mothers" (mães de santo) in Brazilian cinema based on producer Alfredo Sternheim's 1974 film "Pureza Proibida" (Forbidden Purity), and producer João Daniel Tikhomiroff's 2009 movie "Besouro" (Beetle). Based on cultural studies, feminist criticism, and film theory, this paper discusses the intersection of race and gender identities and observes forms of visibility and multiple configurations of the black woman in these audiovisual narratives.

Keywords: black women, brazilian cinema; film analysis.

\section{Crítica Feminista e estudos de comunicação e cinema no Brasil}

Consideradas mecanismos que naturalizam as posições sociais atribuídas às mulheres na cultura e nas relações sociais, as imagens e as narrativas veiculadas pelos meios de comunicação se tornaram objeto de crítica e reflexão dos estudos feministas e de gênero, que surgiram a partir dos anos de 1960. 
Nas décadas seguintes, o estudo pioneiro da teórica feminista Laura Mulvey, "Visual Pleasure and Narrative Cinema", publicado, em 1975, na revista Screen; e publicações posteriores de outras pesquisadoras, como Kaplan (1983), consolidaram a crítica feminista cinematográfica e televisiva, com o propósito de desmistificar o inconsciente patriarcal que estrutura os códigos do cinema clássico e incide na constituição dos papéis sociais e das subjetividades.

Essa função pedagógica do cinema também é analisada por Lauretis (1994), que define o aparelho cinematográfico como uma "tecnologia de gênero". Por meio da montagem, da iluminação, das posições e dos movimentos de câmera, da trilha sonora, e das convenções de espaço e tempo são construídas representações de gênero, capazes não somente de atualizar e naturalizar padrões de beleza e feminilidade, mas moldar corpos e identidades.

No âmbito da pesquisa em comunicação no Brasil, os imaginários construídos sobre os femininos nos meios de comunicação e no cinema têm, desde os anos de 1990, se configurado uma temática, que, segundo Escosteguy e Messa (2008), apesar de ainda tímida, vem ganhando força com estudos principalmente sobre mídia impressa e audiovisual, e que apresentam diferentes abordagens teóricas e metodológicas.

Tais autoras, juntamente com Montoro (2009), revelam as dificuldades para o desenvolvimento de estudos sob a perspectiva de gênero e da crítica feminista, principalmente pela inexistência de um levantamento completo da produção científica nesses campos. Buscando suprir parcialmente essa lacuna, tais autoras realizaram mapeamentos sobre as pesquisas elaboradas nos programas de pós-graduação em comunicação e outras áreas das ciências sociais.

Ao analisar também artigos, capítulos de livros e papers, apresentados em congressos e associações científicas como a Socine e a Compós, no período de 1995 a 2008, Montoro (2009, p. 16) destaca que "há uma escassa produção de teses/ dissertações/artigos que tomem os estudos de gênero no cruzamento com estudos de raça e etnias na análise fílmica e de TV".

Também Escosteguy e Messa (2008) reiteram que a problemática de raça ainda é pouco explorada, e mencionam em seu levantamento os seguintes trabalhos produzidos no período de 1992-2002, que articulam gênero e raça: "O espelho invisível: Um estudo sobre o não reconhecimento das mulheres negras na televisão brasileira", (SCOTTI, 2006); "As Cores da Mulher Negra no Jornalismo: o discurso nos jornais e revista (MELLO SILVA, 2002)"; e "Para além do próprio umbigo: as mulheres negras militantes de Salvador e a construção do imaginário feminino" (SILVA,1998).

Nas pesquisas sobre cinema também se evidencia a primazia do gênero. Esteves (2005) investiga as representações do feminino no cinema de Ana Carolina. A autora analisa a trilogia Mar de rosas (1977), Das tripas coração (1982) e Sonho de valsa (1986), filmes que questionam as relações de poder existentes na esfera familiar, no casamento e nas práticas cotidianas, enaltecendo assim a dimensão política do âmbito privado. 
Veiga (2010) também investiga a produção cinematográfica de Ana Carolina e da cineasta argentina Maria Luisa Bemberg, buscando refletir como tais trabalhos fazem parte de uma memória cinematográfica, voltada para o questionamento das relações hierárquicas e tradicionais de gênero.

Nesse contexto, propõe-se articular esse panorama de ausência do cruzamento de gênero e raça na pesquisa em comunicação e cinema com os imaginários construídos sobre o feminino negro na cinematografia brasileira, com o propósito de identificar ressonâncias, mediações e diferenças entre o exercício feminino do sagrado nas religiosidades afro-brasileiras e as representações audiovisuais sobre "mães de santo"1", a partir das personagens Mãe Cotinha e Mãe Zulmira, retratadas nos filmes Pureza Proibida (Alfredo Sternheim, 1974) e Besouro (João Daniel Tikhomiroff, 2009).

A escolha desses filmes se deve pelo fato de ambos retratarem a liderança religiosa de mulheres negras nos cultos afro, e, principalmente, apontarem diferentes abordagens sobre os femininos e as feminilidades negras no cinema brasileiro, o que se relaciona com as mudanças sociais, culturais e políticas que ocorreram nas últimas décadas no país.

Dessa forma, tal investigação se estrutura primeiramente com uma contextualização acerca da intersecção de gênero e raça na cinematografia nacional; uma apresentação dos filmes escolhidos; e as análises de tais produções audiovisuais, nas quais se busca identificar formas de visibilidade, estratégias de mediação e resistência, afetividades e múltiplas visões do feminino negro.

\section{Gênero e raça no cinema brasileiro}

Apesar de todas as transformações ocorridas na sociedade brasileira, ainda predominam nas narrativas midiáticas e audiovisuais, resquícios de um imaginário patriarcal, que pela ausência (a ínfima participação de profissionais negros/as), ou pela imposição de "lugares" predeterminados (como mão de obra e/ou mercadoria para consumo) invisibiliza a população negra.

Em um dos estudos pioneiros sobre o negro no cinema brasileiro, Rodrigues (2012) estabelece uma classificação de arquétipos e caricaturas do negro no cinema. Dos treze arquétipos apontados, três referem-se ao feminino: "a mãe preta", a "mulata² boazuda" e a "musa".

Companheira do malandro, a mulata boazuda reúne ao mesmo tempo características dos orixás Oxum (beleza, vaidade, sensualidade), Yemanjá (altivez, impetuosidade) e Yansã (ciúmes, promiscuidade, irritabilidade). Em suas formas

\footnotetext{
Mãe de santo é o termo popular dado à lalorixá, chefe do terreiro, sacerdotisa suprema da casa/terreiro de candomblé. Apesar de ser largamente utilizado para designar filhos/as de relações inter-raciais, o termo "mulato/a" tem conotações pejorativas, primeiramente por fazer alusão a mula/jumento (animal considerado um ser estéril, ou seja, confirma a inconveniência de tais relações); e principalmente, em sua versão feminina, reitera a construção social da mulher negra pela ótica do exotismo, como sexualmente disponível.
} 
mais agressivas pode adquirir as atitudes vulgares e debochadas da Pombagira, entidade da umbanda paramentada como um misto de cigana e prostituta. (RODRIGUES, 2012, p. 44-45)

Dessa forma, embora se reconheça a relevância de tal estudo, pode-se considerar que apresenta também simplificações e até mesmo distorções com relação às divindades do universo afro-brasileiro, usadas pelo autor no sentido de "justificar" a existência de tais estereótipos.

A questão racial também é estudada por Carvalho (2008) em sua investigação sobre o cinema novo. De acordo com o autor, a representação do negro e de aspectos de sua cultura e história presentes na maioria dos filmes da primeira fase do Cinema Novo apresenta novas perspectivas de simbolização do Brasil e do negro, com o ingresso de novos atores afro-brasileiros no cinema, alguns destes, mais tarde, também atuariam como diretores, como Zózimo Bulbul, Antonio Pitanga e Valdir Onofre.

Ter um diretor negro não significou, segundo Stam (2008, p. 472), uma maior participação da mulher negra, que ele considera "a ausência mais notável do cinema brasileiro". Nesse âmbito, vale ressaltar também a repercussão do filme Xica da Silva (Cacá Diegues, 1976), que oferece aspectos relevantes para uma reflexão sobre o feminino negro no cinema nacional.

Stam (2008) menciona a visão de Glauber Rocha que chamou o filme de "afro-feminista e libertário"; a de Randal Johnson, que viu nessa narrativa um "questionamento festivo das hierarquias sociais", e também a análise da ativista e historiadora negra, Beatriz Nascimento, "A Senzala vista da Casa Grande", publicada no jornal Opinião, em outubro de 1976.

Para Beatriz Nascimento, a representação da alegre miscigenação dos trópicos em Xica da Silva prolonga a visão rósea de Gilberto Freyre sobre a escravidão brasileira mostrando a "senzala do ponto de vista da casa-grande"

[...] A representação da mulher negra, para Beatriz Nascimento, é altamente negativa. A reação de Xica à discriminação pela Igreja, por exemplo, é infantil. Sua personagem "reforça o estereótipo da negra passiva, dócil e intelectualmente debilitada, que depende dos brancos para pensar". (STAM, 2008, p. 409-410)

O autor confirma a importância de tal posição sobre o filme, mas expõe sua leitura ao enfocar a habilidade de Xica em usar o corpo para conseguir o que deseja, por isso ela pode, segundo Stam (2008) ser vista como uma mulher que desestabiliza as hierarquias sociais convencionais. Além disso, a interpretação de Zezé Motta transmite, de acordo com o autor, um forte sentido de orgulho negro.

Essas diferentes interpretações devem ser observadas, desde que se situe o filme no contexto do racismo e do sexismo existentes na sociedade brasileira, que se revelam nos meios de comunicação e no cinema por meio de uma visibilidade ainda limitada 
para as mulheres negras, ora como objeto sexual, a "mulata"; ora como a empregada doméstica, a "mãe-preta"3.

Essas imagens, segundo Caldwell (2001), servem para naturalizar as desigualdades de gênero e raça e manter a imagem nacional do país como "democracia racial", perspectiva que contrasta com o padrão de feminilidade e beleza predominante na mídia brasileira, mas que evidencia a dimensão política dessa invisibilidade da raça nos estudos feministas e sobre mulheres no Brasil, pois como ressalta a autora, diferentemente dos Estados Unidos, onde as contribuições de mulheres negras e mestiças foram inseridas no pensamento feminista, aqui, a questão racial é ignorada ou relegada à condição de subitem em grande parte da nossa produção teórica e cultural.

O não reconhecimento da importância da raça na configuração de gênero no Brasil se evidencia em uma dupla ausência do feminino negro. Os estudos de cinema sob uma perspectiva feminista nem sempre observam a questão racial; e os poucos estudos sobre cinema e raça no país muitas vezes não consideram a questão de gênero como objeto de pesquisa.

Contudo, é também por meio da análise desses vazios e silêncios existentes na historiografia e no cinema brasileiros, que algumas pesquisas têm revelado uma outra história, composta de lutas e resistências das mulheres negras.

\title{
Mães negras e religiosidade afro-brasileira na cultura e no cinema brasileiro
}

A história oficial, ao mistificar a atuação do feminino negro restrita ao âmbito do corpo e da sexualidade, nega e silencia o protagonismo e a insubordinação das mulheres negras que, diante da escravidão, do racismo, do sexismo e da pobreza, engendraram e ainda hoje elaboram cotidianamente mecanismos de resistência e estratégias de preservação da sua cultura e dignidade.

\begin{abstract}
A luta das mulheres adquiriu diferentes perfis em nossa história, pois diferentes também eram as inserções sociais e as origens étnicas de suas protagonistas. Em comum, traziam o desejo de liberdade. Para as mulheres brancas, foi a luta contra o domínio patriarcal. Para as negras, a luta contra o jugo colonial, a escravidão e o racismo. Dentre as formas de resistências engendradas pelas mulheres negras brasileiras, destaca-se o exemplo das Yalorixás: uma estirpe de notáveis lideranças espirituais, como Yya Nassô (século XIX), Tia Ciata (18541924), Mãe Aninha (1869-1938), Mãe Senhora (1900-1967) e Mãe Menininha do Gantois (1894-1986), entre outras (CARNEIRO, 2007, p. 1).
\end{abstract}

3 A imposição de ser mãe-preta obrigava as mulheres negras a abandonarem seus filhos para amamentar e cuidar das crianças da casa grande. 
Ancorada no entendimento dessa experiência histórica diferenciada, marcada pela interseção das desigualdades de raça, gênero e também classe, é que se propõe uma reflexão sobre o feminino negro nos territórios de pertencimento dos cultos afro-brasileiros, por meio da análise de personagens que atuam como sacerdotisas nos filmes Pureza Proibida (Alfredo Sternheim, 1974) e Besouro (João Daniel Tikhomiroff, 2009), buscando assim investigar como se configuram os trânsitos entre as narrativas audiovisuais sobre os femininos negros no cinema e o imaginário cultural brasileiro.

No livro "Crítica da imagem eurocêntrica", Shohat e Stam (2006) enaltecem que as religiões de origem africana são invariavelmente caricaturadas na cultura dominante. Os autores citam os filmes Orquídea Selvagem (Wild Orchid, Zalman King, 1989) e Feitiço do Rio (Blame it on Rio, Stanley Donen, 1984) que, além de outros clichês acerca da cultura brasileira, reduzem os cultos afro-brasileiros à sensualidade e ao sexo, ao "afro-disíaco". "Na comédia, Feitiço do Rio, vemos um ritual da umbanda que mais parece uma orgia na qual a mãe-de-santo distribui conselhos amorosos aos turistas em inglês" ( ibid., p. 295-296).

Embora confirme a ausência de negros e índios, e suas expressões culturais e religiosas na cultura e no cinema brasileiro, Stam (2008) também apresenta diferentes olhares sobre a religiosidade afro-brasileira na cinematografia nacional, com destaque para a atuação das mães de santo, como por exemplo, Mãe Sabina (interpretada pela mãe de santo Massu) no filme Bahia de todos os santos (Trigueirinho Neto, 1960), que mesmo tendo seu terreiro destruído pela polícia, durante a Era Vargas, a sacerdotisa demonstra uma postura altiva diante das ameaças do delegado.

O primeiro longa de Glauber Rocha, Barravento, também é mencionado pelo autor. Nesse filme, embora o objetivo do diretor seja utilizar a população negra como referencial estético do pobre, e também fazer uma crítica dialética ao candomblé, é a própria narrativa que se rende à riqueza cultural dessa religiosidade de matriz africana, seus mitos, símbolos e, principalmente, a liderança religiosa de "Mãe Dada", revelando assim a contradição entre a intenção do diretor e a composição da obra, que afirma o candomblé como elemento central daquela comunidade de pescadores, já que ultrapassa o espaço do terreiro e influencia a vida de todos/as.

Talvez Barravento já desse indícios do reconhecimento que as expressões culturais e religiosas populares passariam a ter nas décadas seguintes. Tal postura é evidenciada nas diversas obras de ficção e documentário, que tiveram como temática os cultos afros e história da população negra, como, O amuleto de ogum (1974) e Tenda dos Milagres (1977) de Nelson Pereira dos Santos; laô (Geraldo Sarno, 1970), Orí (Raquel Gerber, 1989) e o Fio da Memória (1991), de Eduardo Coutinho.

Também produções televisivas abordaram o universo religioso afro-brasileiro neste período. Em 1985, a Rede Globo exibiu minissérie Tenda dos Milagres, baseada no romance homônimo de Jorge Amado. Escrita por Aguinaldo Silva e Regina Braga, essa minissérie teve a atriz Chica Xavier ${ }^{4}$ no papel da mãe de santo Magé Bassã;

4 Na novela Duas Caras (de Aguinaldo Silva, exibida pela Rede Globo em 2007/2008), Chica Xavier interpreta outra mãe de santo, "Dona Setembrina". 
e em 1990, a TV Manchete exibiu a minissérie Mãe de Santo. Escrita por Paulo César Coutinho, essa produção foi composta por 16 capítulos, que, sob a narração de uma ialorixá interpretada pela atriz Zezé Motta, ${ }^{5}$ abordava as divindades do candomblé.

\section{Análises dos filmes: $o$ feminino e o sagrado no cinema}

As personagens "Mãe Cotinha" e "Mãe Zulmira" (respectivamente dos filmes Pureza Proibida e Besouro) têm em comum a liderança religiosa e principalmente, as relações de cuidado, proximidade e afeto que tais matriarcas desenvolvem com os outros personagens.

Dirigido por Alfredo Sternheim, Pureza Proibida aborda o envolvimento de irmã Lúcia (uma religiosa católica, interpretada por Rossana Ghessa) com o pescador Chico (Zózimo Bulbul). Eles enfrentam a oposição das outras freiras e o ciúme de Anésia, personagem que nutre um amor não correspondido por Chico, e recorre à Mãe Cotinha (Ruth de Souza) para tentar conquistá-lo.

Com o objetivo de retratar a história de Manoel Henrique Pereira (capoeirista mais conhecido como Besouro Mangangá ou Besouro Cordão de Ouro), o diretor João Daniel Tikhomiroff leva para o cinema esse símbolo da resistência negra, que após a morte de mestre Alípio, recebe a missão de continuar lutando contra as injustiças dos antigos senhores, no Recôncavo Baiano de 1920. E quem vai ajudá-lo é Mãe Zulmira (Geisa Costa) e as divindades afro-brasileiras.

A análise fílmica proposta ancora-se na escolha de sequências específicas de cada filme, que se configurem como unidades fundamentais, capazes de revelar a totalidade das narrativas audiovisuais (Casseti; Di Chio, 2007).

A partir dessas sequências, busca-se identificar: (a) a forma como os imaginários sobre o feminino negro são inseridos e retratados na narrativa; (b) as relações, mediações, afetos e estratégias de subversão que tais personagens desenvolvem nos territórios de pertencimento dos cultos afro; e (c) os processos de conformação e transformação de imaginários no cinema brasileiro em diferentes momentos históricos (anos de 1970 e 2000).

\section{Mãe Cotinha: liderança religiosa, mãe de todos}

Essa matriarca é constantemente mencionada pelos personagens como alguém a quem se pode recorrer para a resolução dos mais diversos problemas. Também com esse objetivo é que Anésia, inconformada com a rejeição de Chico, pede-lhe ajuda. Porém, Mãe Cotinha orienta a jovem a se esquecer do rapaz, pois se trata de uma determinação de Oxum (orixá feminino que rege o amor, o dinheiro e a fertilidade).

5 Além desse personagem, a atriz Zezé Motta interpretou também outra líder religiosa do candomblé, "Mãe Ricardina" na novela Porto dos Milagres (escrita por Aguinaldo Silva, Glória Barreto e Ricardo Linhares, exibida em 2001) e recentemente "Tia Celeste", mãe pequena do terreiro de Mãe Marina, na microssérie O Canto da Sereia (escrita por George Moura, Patrícia Andrade e Sergio Goldenberg e exibida em janeiro de 2013). 
Como porta-voz dos desígnios divinos, a matriarca tem a responsabilidade de zelar por aquela comunidade e seus moradores. Tal função é legitimada pelo conhecimento que a personagem tem do uso terapêutico de ervas e plantas, com as quais realiza as curas físicas e espirituais.

Interessada em tais saberes, Irmã Lúcia (que além de religiosa, é também estudante de enfermagem) procura Mãe Cotinha e vai até sua casa aprender com ela sobre o uso medicinal das folhas e ervas. Pode-se considerar que a narrativa dê indícios de um possível reconhecimento da liderança religiosa afro-brasileira, visto que em vez de criar uma assimetria de poder entre as duas personagens, coloca-as juntas no centro do quadro.

Um dos momentos mais significativos da atuação de Mãe Cotinha é a festa que ela oferece para São Cosme e São Damião (Figura 1), na qual aparece centralizada no enquadramento, e de maneira imponente canta um ponto de Umbanda para aqueles que participam do louvor às divindades infantis católicas, também reverenciadas nos cultos afro-brasileiros.
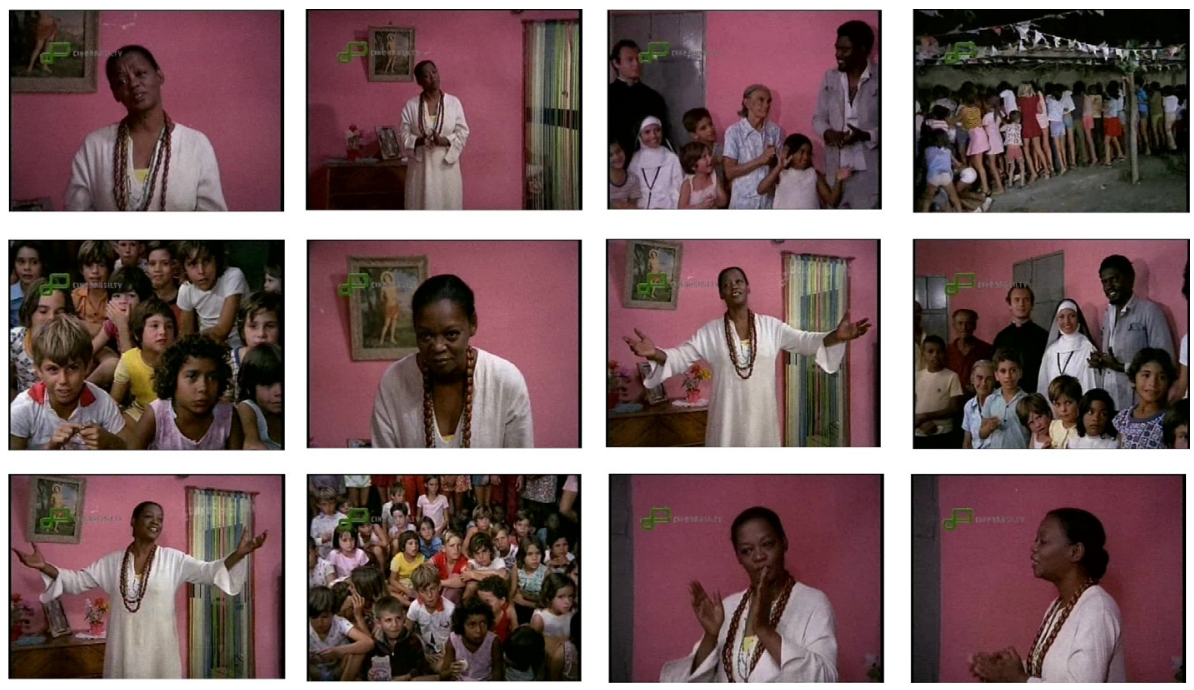

Fig. 1. Festa de Cosme e Damião na casa de Mãe

A parede cor de rosa, a cortina com fios coloridos e as imagens dos santos meninos são aspectos que fazem alusão ao universo infantil e também compõe outro ambiente da casa de Mãe Cotinha, território que agrega ao mesmo tempo as funções doméstica e religiosa, revelando a relação com o sagrado como uma experiência indissociável de sua vida cotidiana, também uma peculiaridade dos cultos afro-brasileiros.

Segundo Theodoro (1996, p. 169-170), "seja na comunidade-terreiro, em seu espaço de moradia ou no trabalho, a mulher negra engendra um conhecimento de si e do mundo através de representações reais e imaginárias, instituindo suas diferenças e construindo sua identidade". 
A disposição dos personagens no enquadramento é um aspecto relevante nesta sequência, visto que Mãe Cotinha está cantando sozinha de um lado, enquanto os demais integrantes estão no lado oposto. Além disso, a participação de irmã Lúcia e padre José, e de outros moradores da comunidade confirmam o protagonismo dessa matriarca, que pelas relações de afeto e solidariedade que desenvolve com todos, ultrapassa os territórios de pertencimento dos cultos afro.

\section{Outras feminilidades negras}

Embora não esteja diretamente relacionada à sacerdotisa analisada, vale ressaltar uma passagem em que Anésia faz um despacho, com o objetivo de conquistar o amor de Chico. Alguns elementos que compõe essa oferenda (bebida alcóolica e cigarro), o ritmo percussivo da trilha sonora, o uso da cor vermelha no figurino e a gestualidade empregada pela personagem em tal sequência (Figura 2), podem ser considerados uma alusão à Pombagira.
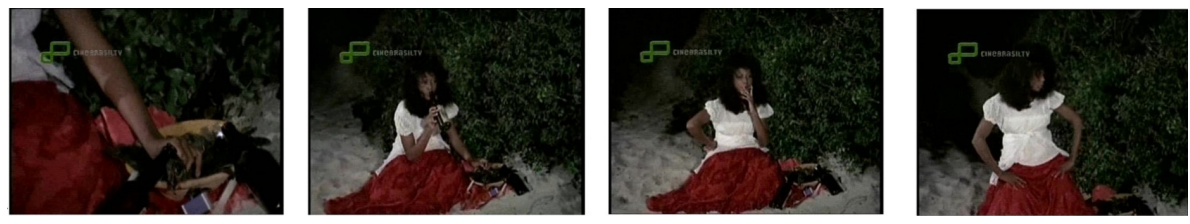

Fig. 2. Anésia e referência à Pombagira

Ao apontar as origens históricas de "Maria Padilha", um dos nomes dessa conhecida entidade $^{6}$ da Umbanda, Meyer (2001) revela a força dessa referência feminina, tão presente no imaginário cultural e religioso brasileiro.

Maria Padilha, ou Padilha. Nome da preferida de um rei de Castela do século XIV, cantada em versos nos velhos romances espanhóis. Nome que aparecia em conjuros de feiticeiras portuguesas degredadas no Recife no século XVIII e invocada pela Carmen de Mérimée (a de Bizet) quando ela mexia em seus filtros mágicos. Nome enfim de uma pomba-gira de umbanda. Quase rainha, feiticeira, mulher de Lúcifer, prostitutriz ou encantada, Maria Padilha é sempre uma mulher forte, bela, sedutora, dotada de altos poderes. (MEYER, 2001, p. 227)

6 O termo "entidade" designa, segundo Prandi (1996), uma infinidade de espíritos de mortos e seres sobrenaturais (como por exemplo, exus, caboclos, boadeiros, pretos-velhos, guias de luz, etc.) cultuados na Umbanda, e com os quais os fiéis brasileiros podem estabelecer relações religiosas e mágicas e contatos personalizados, especialmente através de cerimônias em que essas entidades se apresentam através do transe, ou seja, incorporam em seus "cavalos" (médiuns). 
Contrariando os modelos de feminilidade vigentes, nos quais a mulher ideal é aquela que tem seu corpo e sua sexualidade controlados, a Pombagira emerge como uma inversão simbólica. Associada a elementos mundanos, como o fogo, a cor vermelha, bebidas, cigarros, festas e sexo, essa entidade é retratada como uma mulher de vários homens.

Ao analisar as representações de gênero nas manifestações da Pombagira, Lagos (2007) ressalta que essa entidade, na sua condição de livre e libertina ajuda todas aquelas que lhe procuram para a resolução de problemas domésticos, sexuais e financeiros, tem assim uma função de intermediadora das relações amorosas, vinculadas ao poder de uma feminilidade não passível de ser "formatada".

\section{Mãe Zulmira: elo entre deuses e humanos}

Essa personagem ocupa um papel central na narrativa de Besouro, o que é evidenciado pela reverência que outros personagens Ihe prestam, ao pedir-lhe a benção, ato comum nas religiões de matriz africana, e que significa o respeito à autoridade e à experiência dos mais velhos.

Após um embate com os capangas do coronel Venâncio, Besouro foge pulando de um precipício em um rio, o que faz seus opositores darem por certo sua morte. Porém, ele reaparece sob as águas. Tal sequência se constitui numa montagem paralela que sob a narração de mestre Alípio alia cenas de Besouro no rio, sendo cuidado pelos orixás; e em outro ambiente, onde recebe os cuidados de Mãe Zulmira (Figura 3).

De forma poética, o narrador fala para Besouro e também para o espectador o que são os orixás, ${ }^{7}$ juntamente com imagens que revelam as características, os elementos da natureza que tais divindades regem, e, principalmente, mostra como a partir de seus domínios (as folhas, os rios, os ventos e os metais) oferecem auxílio ao protagonista (Figura 3).

Por meio das cores e adereços, o filme apresenta e articula discursos e elementos visuais das divindades femininas (iabás), que são reverenciadas pelo capoeirista de formas diferentes, de acordo com as características de sua personalidade (flores amarelas para Oxum e vermelhas para lansã). Além disso, as cenas que acompanham a narração reiteram as características apontadas, como por exemplo, o movimento das águas do rio sobre o corpo de Besouro faz alusão ao caráter maternal e protetor de Oxum, como se ela o embalasse em seus braços; assim como a ação de fazer o capoeirista levitar pode estar relacionada à força e ao caráter guerreiro de lansã.

7 A narração fala de Ossain, Ogum, Oxum e lansã, apesar de Exu também ser mostrado. Este orixá, que rege os caminhos, e também agrega o poder da mudança e da continuidade aparece em sequências que antecedem a esta e com uma postura provocadora parece ter a função de instigar o protagonista para a missão que ele deve seguir. 

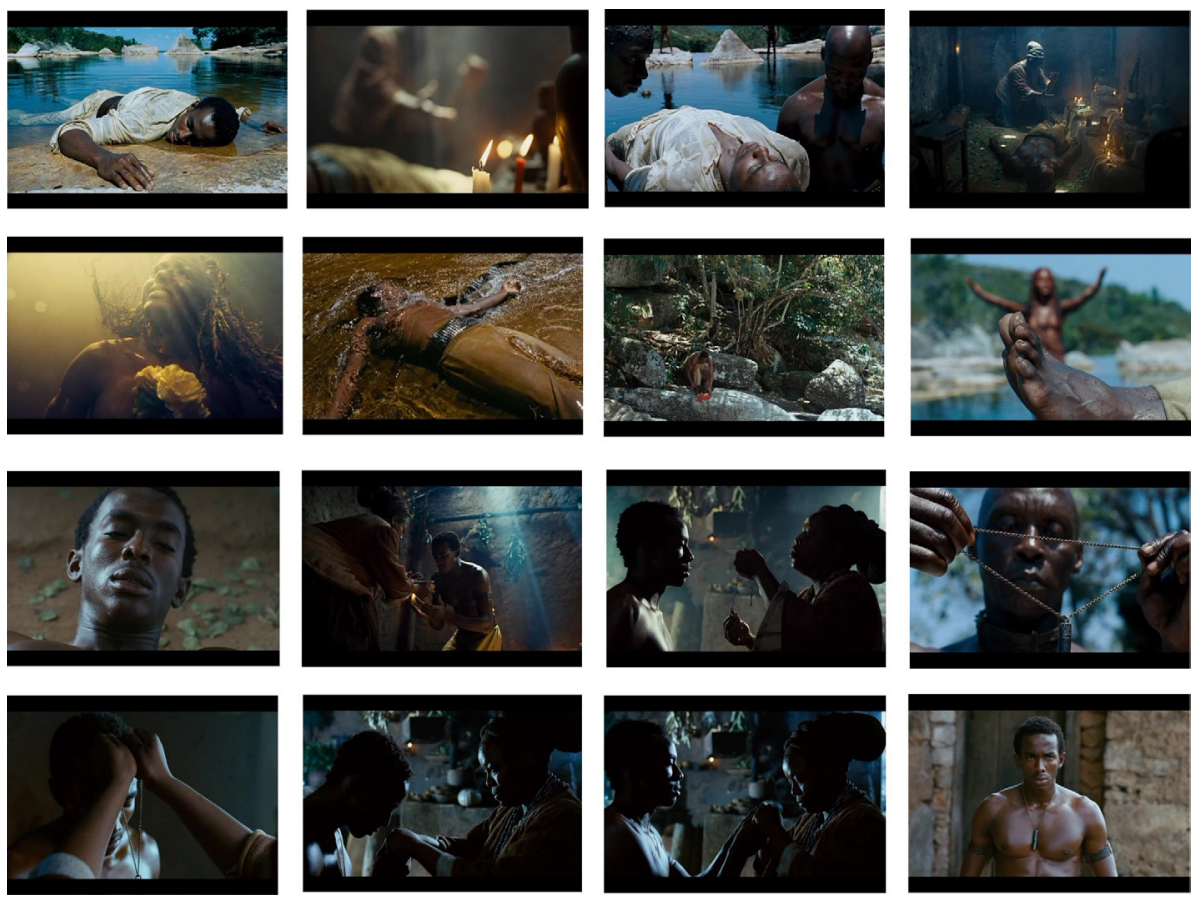

Fig. 3. Mãe Zulmira e orixás cuidam de Besouro

Ao afirmar que "a capoeira por si só não livra ninguém da maldade", Mãe Zulmira confirma a importância da religiosidade como "alimento" do corpo e da luta empreendida nos negros.

O colar de metal, que nas cenas anteriores foi utilizado pelos orixás Ossaim e Ogum para tratar o corpo de Besouro, agora é dado a ele por Mãe Zulmira. Ela enfatiza o significado daquele objeto, que passa a ser a proteção dele, pois foi "dormida aos pés de Ogum" (o orixá que rege a cabeça do protagonista) (Figura 3). Essa sequência destaca a estreita relação entre orixás e humanos e enaltece o papel fundamental de Mãe Zulmira, é ela quem tem o poder e o saber de chamar as divindades.

De acordo com Joaquim (2007, p. 15-16), “acrescido ao significado do papel de mãe encontra-se o fator de dar a vida, fazer o Santo, ou seja, o acesso à comunicação com os Orixás, que se complementa com os adjetivos de provedora, acolhedora, educadora. Enfim, é quem fornece o aconchego a todas as pessoas".

Ao pedir a benção à Mãe Zulmira, Besouro reverencia a autoridade e sabedoria dessa matriarca, que demonstra reciprocidade ao jovem. Na última cena, Besouro aparece no centro do quadro e como se caminhasse em direção à câmera, mostra que está fortalecido e pronto para a luta. 


\section{Outras mães negras}

Além de Mãe Zulmira, a narrativa de Besouro oferece também outras imagens de mães negras, com as personagens Teresa e Dinorah (Figura 4). Mãe e filha são empregadas na casa do coronel Venâncio e lidam de maneiras diferentes com o assédio e a opressão por parte deste e de outros personagens da "Casa Grande".
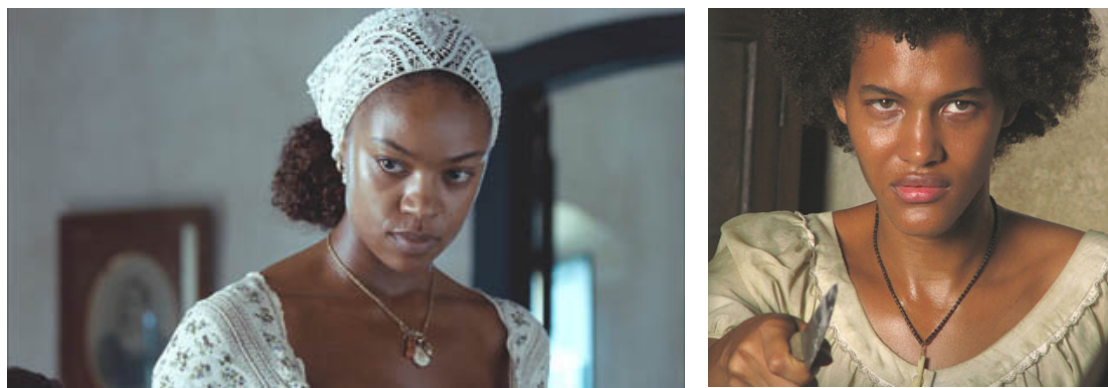

Fig. 4. Teresa e Dinorah

Teresa (Cris Viana) demonstra uma postura aparentemente passiva, porém, pode-se considerar que talvez esta seja um mecanismo de sobrevivência diante do contexto de perseguição e violência que ainda predominava sobre homens e mulheres negros, mesmo após a abolição da escravatura. Já Dinorah ${ }^{8}$ (par romântico de Besouro) explicita em vários momentos da narrativa sua indignação e reage a uma tentativa de estupro por parte do coronel Venâncio. Grávida do protagonista, ela usa a capoeira como estratégia de defesa. Logo, pode-se considerar algumas semelhanças entre essa personagem e as característica de lansã.

\section{Palavras finais}

Investigar os repertórios audiovisuais do feminino negro no cinema brasileiro, a partir das mães de santo da ficção significa pensar sobre o significado da maternidade para as mulheres negras. A destruição dos laços de parentesco e a imposição das funções de objeto sexual ou mãe-preta negaram-lhes tal função, posteriormente invisibilizada também na historiografia, na literatura, nos meios de comunicação e também no cinema, no qual ainda prevalecem essas visões.

Entretanto, foi por meio da reconstituição da família (real ou simbólica) que a mulher negra desenvolveu estratégias de sobrevivência e resistência. A família-de-santo e o terreiro de candomblé possibilitaram-Ihes restituir sua humanidade, seus afetos e memórias.

8 Essa personagem é vivida por Jessica Barbosa, atriz que também interpreta o orixá lansã. 
Esse exercício feminino do sagrado e seu protagonismo se fazem presentes, mesmo em produções hegemônicas, como nos dois filmes analisados, o que reitera a amplitude das representações audiovisuais, que agregam também ambiguidades, polissemias e devires.

O destaque dado a uma mãe de santo em um longa de ficção de 1974, cujo objetivo não era retratar as religiões afro-brasileiras pode apontar outros indícios desse período histórico que, apesar da ditadura, foi significativo para a formação dos movimentos negros no país. Nascimento (apud RATTS, 2007, p.64), ressalta que "[...] na década de 70, éramos mudos. E os outros eram surdos a nós. A partir de 70, começamos a falar sociologicamente [...]".

Mais de trinta anos depois, Besouro retrata a história de um ícone da resistência negra e constrói toda a sua narrativa no universo religioso, cultural e mítico afro-brasileiro, aspectos que inserem tal produção no contexto das mudanças ocorridas na sociedade brasileira nas últimas décadas, com destaque para as conquistas dos movimentos negros, com a implementação de ações afirmativas para a população negra; e também a constante reflexão pública sobre as políticas de representação para atrizes e atores negros na mídia e no cinema.

A partir desses dois filmes, pode-se considerar que houve avanços na representação da população negra, mesmo que ainda pequenos. Porém, no que se refere à participação como produtores, cineastas e diretores, iniciativas como o Manifesto Dogma Feijoada9 (lançado em 2000) reiteram a preocupação com o monopólio da produção audiovisual brasileira.

Além do protagonismo e do cuidado de Mãe Cotinha com todos os moradores daquela comunidade, o filme Pureza Proibida aponta ainda a tão temida e admirada figura da Pombagira, referência de feminilidades que não se enquadram nos papéis sociais preestabelecidos, são donas de seu corpo, de sua sexualidade e de seu destino.

Em Besouro, a atuação das personagens Mãe Zulmira, Teresa e Dinorah, juntamente com as referências estéticas às iabás, especialmente Oxum e lansã, com suas cores, simbologias e mitos alargam e complexificam a compreensão tradicional de feminino. Tais divindades são guerreiras habilidosas, amantes apaixonadas e mães dedicadas.

Apesar desses filmes não se referirem às religiões afro (Umbanda e Candomblé) de forma institucionalizada, revelam as relações de pertencimento, a liderança das mães negras e, especialmente, a pluralidade de femininos e feminilidades negras, aspectos que aproximam essas duas produções de temporalidades distintas.

As complexidades e contradições que emergem de personagens e outros elementos das narrativas audiovisuais podem despertar novos olhares, fluxos e percepções acerca do protagonismo feminino no cinema brasileiro. Como foi possível observar nos filmes analisados, essas matriarcas negras são ponto de referência e união, são guardiãs e provedoras de uma memória ancestral. Contrariando o racismo e o sexismo, as mulheres negras encontram no sagrado um território de empoderamento e de afirmação de sua identidade feminina e negra.

9 Inspirado no Dogma 95 (Movimento cinematográfico lançado pelos cineastas Lars von Trier e Thomas Vinterberg, que propunha a criação de um cinema mais simples, anti-ilusionista e antiautoral), o Dogma Feijoada proclamava sete mandamentos ou regras para o cinema negro, entre eles, ser dirigido por um realizador negro e evitar personagens estereotipados negros (ou não). 
Tania Montoro é PHD em Cinema e Televisão pela Universidade Autônoma de Barcelona e professora e pesquisadora de Teoria do Cinema na Graduação em Audiovisual e no Programa de Pós-Graduação em Comunicação da UnB.

taniamontoro@unb.br

Conceição de Maria Ferreira Silva (Ceiça Ferreira) é jornalista e doutoranda em Comunicação na UnB; é bolsista Reuni/Capes.

ceicaferreira@gmail.com

\section{Referências}

CALDWELL, K. L. Racialized Boundaries: Women's Studies and the Question of Difference in Brazil. Journal of Negro Education, n.70 (3), p. 219-230, 2001.

CARNEIRO, S. A força das mães negras. Le Monde Diplomatique, 8 nov. 2007. Disponível em: <http:// www.diplomatique.org.br/artigo.php?id=79>. Acesso em: 20 set. 2013.

CARVALHO, N. dos S. Racismo e anti-racismo no Cinema Novo. In: HAMBURGUER, et al.(orgs.). Estudos de Cinema Socine. São Paulo: Anablume, 2008, p. 53-60. 9 v.

CASETTI, F.; DI CHIO, F. Como Analizar un Film. Barcelona: Paidós Comunicación 172 Cine, 2007.

ESCOSTEGUY, A. C.; MESSA, M. R. Os estudos de gênero na pesquisa em comunicação no Brasil. In: ESCOSTEGY, A. C. (org.). Comunicação e gênero: a aventura da pesquisa [recurso eletrônico]. Porto Alegre: EDIPUCRS, 2008, p.14-29.

ESTEVES, F. C. Visualidade, gênero e poder: as representações do feminino no cinema de Ana Carolina ("Mar de rosas", "Das tripas coração" e "Sonho de valsa"-1977 a 1986). História, Imagens e Narrativas, n. 1, ano 1, 2005.

JOAQUIM, M. S. O Papel da liderança religiosa feminina na construção da identidade negra. Rio de Janeiro: Pallas, 2001.

KAPLAN, E. A. Women \& Film. Both Sides of the Camera. London: Methuen, 1983.

LAGOS, N. M. L. "Arreda homem que aí vem mulher...". Representações de gênero nas manifestações da Pombagira. 2007. 130 f. Dissertação (Mestrado em Ciências da Religião) - Universidade Metodista de São Paulo, São Paulo.

LAURETIS, T. de. A tecnologia do gênero. In: HOLLANDA, H. B. de. Tendências e Impasses: o feminismo como crítica da cultura. Rio de Janeiro, Rocco, 1994, p. 206-242.

MELLO SILVA, E. As cores da mulher negra no jornalismo: o discurso nos jornais e revista. Dissertação, USP, 2002.

MEYER, M. Caminhos do Imaginário no Brasil. 2. ed. São Paulo: Editora da Universidade de São Paulo, 2001.

MONTORO, T. Protagonismos de gênero nos estudos de cinema e televisão no País. Revista Lumina, n. 2, v.3, p. 1-18, 2009. 
MULVEY, L. Visual Pleasure and Narrative Cinema. Screen, v. 16, n. 3, p. 6-27, 1975.

PRANDI, R. Herdeiras do Axé: sociologia das religiões afro-brasileiras. São Paulo: Ed. Hucitec, 1996.

RATTS, A. Eu sou atlântica: sobre a trajetória de vida de Beatriz Nascimento. São Paulo: Imprensa Oficial de São Paulo/ Instituto Kuanza, 2007.

RODRIGUES, J. C. O negro brasileiro e o cinema. 4. ed. Rio de Janeiro: Pallas, 2012.

SCOTTI, E. O espelho invisível: um estudo sobre o não reconhecimento das mulheres negras na televisão brasileira. Monografia de conclusão em Jornalismo, FAMECOS/PUCRS, 2006.

SHOHAT, E.; STAM, R. Crítica da Imagem Eurocêntrica. Tradução Marcos Soares. São Paulo: Cosac Naify, 2006.

SILVA, E. B. Para além do próprio umbigo: as mulheres negras militantes de Salvador e a construção do imaginário feminino. Dissertação, UFBA, 1998.

STAM, R. Multiculturalismo Tropical: Uma História Comparativa da Raça na Cultura e no Cinema Brasileiro. São Paulo: Editora da Universidade de São Paulo, 2008.

THEODORO, H. Mito e Espiritualidade: mulheres negras. Rio de Janeiro: Pallas Editora, 1996.

VEIGA, A. M. Gênero e cinema: uma abordagem sobre a obra de duas diretoras sul-americanas.

Cadernos de Pesquisa Interdisciplinar em Ciências Humanas, n. 11 (98), p.111-128, 2010.

Artigo recebido em julho e aprovado em dezembro de 2013. 